Proceedings

\title{
Porous Silicon Biosensor for the Detection of Bacteria through Their Lysate ${ }^{\dagger}$
}

\author{
Roselien Vercauteren ${ }^{1, *}$, Audrey Leprince ${ }^{2}$, Jacques Mahillon ${ }^{2}$ and Laurent A. Francis 1 \\ 1 Institute of Information and Communication Technologies, Electronics and Applied Mathematics, \\ UCLouvain, 1348 Louvain-la-Neuve, Belgium \\ 2 Laboratory of Food and Environmental Microbiology, Earth and Life Institute, UCLouvain, 1348 Louvain- \\ la-Neuve, Belgium \\ * Correspondence: roselien.vercauteren@uclouvain.be \\ † Presented at the First International Conference on “Green” Polymer Materials 2020, 5-25 November 2020; \\ Available online: https://cgpm2020.sciforum.net/.
}

Received: date; Accepted: date; Published: date

\begin{abstract}
Porous Silicon (PSi) has been widely used as a biosensor over the last years due to its large surface area and its optical properties. Most PSi biosensors consist in close-ended porous layers and, because of the diffusion-limited infiltration of the analyte, they lack sensitivity and speed of response. In order to overcome these shortcomings, PSi membranes (PSiMs) have been fabricated using electrochemical etching and standard microfabrication techniques. In this work, PSiMs have been used for the optical detection of Bacillus cereus lysate. Before detection, the bacteria are selectively lysed by PlyB221, an endolysin encoded by the bacteriophage Deep-Blue targeting $B$. cereus. The detection relies on the infiltration of bacterial lysate inside the membrane, which induces a shift of the effective optical thickness. The biosensor was able to detect a B. cereus bacterial lysate, with an initial bacteria concentration of $10^{6}$ colony forming units per $\mathrm{mL}(\mathrm{CFU} / \mathrm{mL})$, in less than 10 min. This work also demonstrates the selectivity of the lysis before detection. Not only does this detection platform enable the fast detection of bacteria, but the same technique can be extended to other bacteria using selective lysis.
\end{abstract}

Keywords: Porous Silicon membrane; bacteria detection; selective lysis; endolysins; flow-through.

\section{Introduction}

A biosensor allows the fast detection and quantification of a biological analyte, without preenrichment steps. It is characterized by two components: a biological element, which is often key to the selectivity, and a transducer [1]. The biological element frequently takes the form of a bioreceptor, which is bound to the surface of the transducer. This binding requires several steps of surface modification or functionalization, which can be complex, time-consuming and/or expensive. On top of that, functionalization can shorten the lifespan of the biosensor and often puts heavy requirements on the storage conditions. These bottlenecks can be avoided by adding the biological element into the sample volume instead of binding it to the transducer. Among these biological elements are endolysins: produced by bacteriophages or bacterial cells, they have the capability to specifically digest the cell wall of specific bacterial strains. They have proven to be powerful selectivity means for the detection of bacteria [2-4].

Porous Silicon (PSi) is a widely used optical transducer for biosensors [5,6]. Its benefits include a large surface area, unique optical properties and a low production cost. Most PSi-based optical transducers rely on changes in the refractive index, which occurs when an analyte penetrates the porous matrix, as means of detection. This change can be quantified using reflective interferometric Fourier transform spectroscopy (RIFTS) [7]. The RIFTS method consists in shining a halogen light 
perpendicularly to the sensors' surface and measuring its reflection. The reflection takes the form Fabry-Pérot fringes due to the interferences between the light reflections from the top and the bottom interfaces of the porous film. By applying a Fourier transform to this fringe pattern, is it possible to extract their frequency, which takes the shape of a peak. The position of this peak translates the effective optical thickness (EOT) of the porous layer, which depends on its thickness and its refractive index.

Recent works using the RIFTS as transducing mechanism of PSi-based transducers target the detection of, for instance, bacterial surface proteins [8], heat shock protein 70 [9], or bovine mastitis biomarkers $[10,11]$ but this method has also been applied for the detection of bacteria [12-14]. These bacteria detectors however lacked sensitivity, with detection limits unable to go below $10^{3}$ colony forming units per $\mathrm{mL}(\mathrm{CFU} / \mathrm{mL})$. Current bacteria detection techniques, such as polymerase chain reaction (PCR) or enzyme-linked immunosorbent assay ELISA, while time-consuming, can easily reach detection limits of $10 \mathrm{CFU} / \mathrm{mL}$ [15]. This insufficient sensitivity is attributed to the hindered diffusion of bacteria into the porous matrix. Solutions, such as the electrokinetic transport for the preconcentration of analyte, have been proposed but remain to be tested on bacteria [16].

Another approach to increase the sensitivity of PSi biosensor is the fabrication of PSi membranes (PSiMs). Instead of a close-ended PSi layer over which the analyte must flow, an open-ended PSi membrane allows the analyte to flow through the porous matrix. PSi membranes have been fabricated as early as the 1990s [17] but the interest in PSiMs for sensing applications only arose recently [18-22]. PSiMs can be self-supported, meaning still partly attached to the silicon substrate, or freestanding. Recently, lateral PSiMs have also been fabricated [23-25]. For biosensing applications, PSiMs have been found to increase both the response time and amplitude of the sensors [18-22].

In this work, we combine the benefits of selective endolysins and PSiM-based transducers for the fabrication of an innovative biosensor which enables the fast and label-free detection of bacteria through their lysate. The biosensing platform operates in two steps: a first step is the selective lysis of the targeted bacteria by an endolysin in a vial; and secondly, the optical monitoring of the bacterial lysate filtering through a PSiM using the RIFTS method. We demonstrate this concept with a selective optical detection of B. cereus lysate in PBS using the recently characterized PlyB221 endolysins, encoded by the Deep-Blue phage targeting B. cereus [26]. The selectivity is confirmed by replacing the targeted bacteria with Staphylococcus epidermidis, for which no optical detection was observed.

\section{Materials and Methods}

\subsection{Materials}

Double side polished, boron doped silicon wafers $(\langle 100\rangle, 0.8-0.9 \mathrm{~m} \Omega \mathrm{cm}, 380-400 \mu \mathrm{m})$ were purchased from Sil'tronix Silicon Technologies (France). Aqueous hydrofluoric acid (HF, 49\%) was acquired from Chem-Lab, nv (Belgium), and absolute ethanol was obtained from VWR Chemicals (France). Phosphate buffered saline (PBS, $0.01 \mathrm{M}$ phosphate, $\mathrm{pH}$ 7.4) was purchased from SigmaAldrich (USA).

\subsection{Fabrication of Porous Silicon layers}

The PSi layer samples were prepared by the electrochemical etch of a heavily doped $p$-type silicon substrate. The etching was carried out in a custom-made Teflon ${ }^{\circledR}$ single bath etch-cell, with a platinum coil as the counter-electrode and a potentiostat/galvanostat (PGSTAT302N from Metrohm Belgium nv, Belgium) as the current source. The porosification was performed in HF:ethanol (3:1, in volume) electrolyte. The first step of the anodization consisted in etching a sacrificial layer at 200 $\mathrm{mA} / \mathrm{cm}^{2}$ for $30 \mathrm{~s}$ and removing it with a $2 \mathrm{M}$ solution of $\mathrm{KOH}$ until no more reaction was visible. This sacrificial layer removes the transitional layer and obtains a more homogeneous pore size with depth. The sample was then rinsed once in deionized water and twice in 2-propanol before being etched 
again at $200 \mathrm{~mA} / \mathrm{cm}^{2}$ for $50 \mathrm{~s}$. The porous samples were thermally oxidized for $30 \mathrm{~min}$ at $350{ }^{\circ} \mathrm{C}$ under an oxygen flow $(1.2 \mathrm{~L} / \mathrm{min})$.

\subsection{Fabrication and Characterization of Porous Silicon Membranes}

Figure 1 sketches the process flow, which was inspired by the work from Zhao et al. [18]. First, 3in. highly doped $p$-type silicon wafers were cleaned in a freshly prepared piranha solution $\left(\mathrm{H}_{2} \mathrm{O}_{2}: \mathrm{H}_{2} \mathrm{SO}_{4}, 2: 5\right)$, followed by two immersions in continuously flowing deionized (DI) water during $20 \mathrm{~min}$. Afterwards, $500 \mathrm{~nm}$ of silicon nitride $\left(\mathrm{Si}_{3} \mathrm{~N}_{4}\right)$ was deposited using Plasma Enhanced Chemical Vapor Deposition (PECVD). To improve the chemical resistance of the nitride layer to HF, the wafers were annealed at $900{ }^{\circ} \mathrm{C}$ in ambient air for $3 \mathrm{~h}$. A first optical lithography with positive resist provided masking for the subsequent Reactive Ion Etching (RIE) of the silicon nitride layer. The patterned nitride layer itself served as mask during the electrochemical etch of the silicon. The porosification followed the same protocol as explained in Section 2.2, but used three different current densities in order to obtain different porosities: the sensing layer was etched at $200 \mathrm{~mA} / \mathrm{cm}^{2}$ for $50 \mathrm{~s}$; this was followed by a $1500 \mathrm{~s}$-etch at $50 \mathrm{~mA} / \mathrm{cm}^{2}$, making a thick optical contrast layer characterized by lower porosity, enabling the reflection of the light required for the RIFTS method; finally, a thick mechanical support layer was etched at $100 \mathrm{~mA} / \mathrm{cm}^{2}$. The porous multilayers were passivated by thermal oxidation, for $30 \mathrm{~min}$ at $350{ }^{\circ} \mathrm{C}$ under an oxygen flow of $1.2 \mathrm{~L} / \mathrm{min}$. A second optical lithography was then performed on the backside of the wafers, where a thick resist was patterned in alignment with the frontside. The thick resist served as mask during the final step of the process, the Deep Reactive Ion Etching (DRIE) of the backside of the wafer, until the Porous Silicon was visible and the membrane were open.

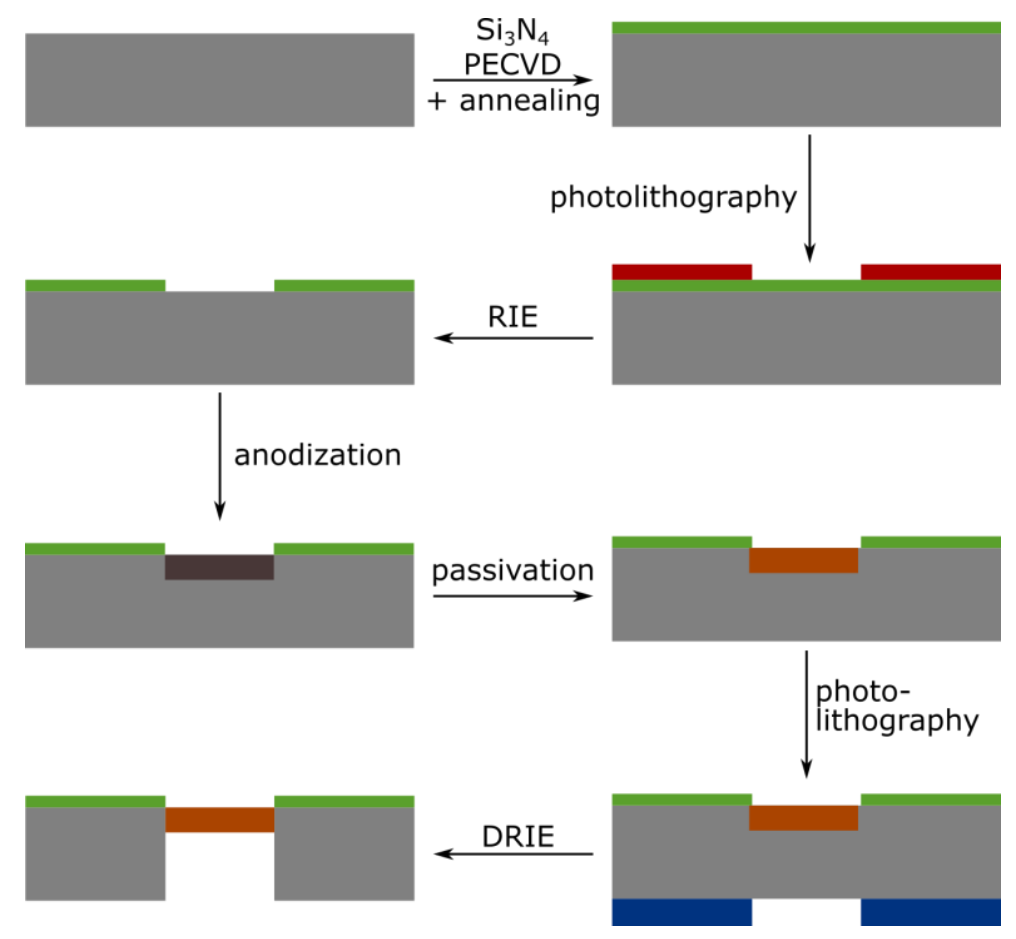

Figure 1. Schematic illustration of the process flow for the fabrication of a Porous Silicon membrane. Starting from a cleaned 3-in highly doped silicon wafer, the process goes through the following steps: deposition of $\mathrm{Si}_{3} \mathrm{~N}_{4}$ layer using PECVD and annealing; positive photolithography on the frontside; opening of the nitride layer using RIE; formation of the Porous Silicon layer by anodization; passivation by thermal oxidation; positive photolithography on the backside; and finally opening of the membrane using DRIE. 
The membranes were characterized using scanning electron microscopy, both in cross section and in top view. Based on the top views, the pore size distribution could be analyzed using the ImageJ software. The porosity of each layer was determined using the spectroscopic liquid infiltration method (SLIM). In brief, the optical spectrum of a porous layer was recorded both in air and in ethanol. Using the RIFTS method described above, the EOT was calculated. Knowing the refractive indices of air, ethanol and silicon, this data was then fitted using a two-component Bruggeman effective medium approximation in order to obtain an approximation of the open porosity and the layer thickness. The experimental set up used for the SLIM method consisted in a fiber-coupled Ocean Optics JAZ spectrometer and a halogen light source.

\subsection{PlyB221 Endolysin Expression and Purification}

A detailed description of the expression and purification of PlyB221 endolysins can be found elsewhere [26]. The protein concentration was adjusted to $1 \mathrm{mg} / \mathrm{mL}$.

\subsection{Bacterial Strains, Growth Conditions and Lysis}

B. cereus ATCC 10987 was used as reference strain for this study and Staphylococcus epidermidis ATCC 35984 was used as negative control. Bacteria were grown overnight $(\mathrm{O} / \mathrm{N})$ in Lysogeny Broth (LB) or LB-agar plates at $30^{\circ} \mathrm{C}$ for B. cereus and in Tryptic Soy Broth (TSB) or Tryptic Soy Agar (TSA) plates at $37^{\circ} \mathrm{C}$ for S. epidermidis. In brief, $20 \mathrm{~mL}$ of LB or TSB were inoculated with $200 \mu \mathrm{L}$ of each culture and incubated for $3 \mathrm{~h}$ at $30^{\circ} \mathrm{C}$ (B. cereus) or $37{ }^{\circ} \mathrm{C}$ (S. epidermidis). The cultures were then centrifuged at $10000 \mathrm{x} g$ for $5 \mathrm{~min}$ at room temperature and the supernatant were resuspended in 20 $\mathrm{ml}$ of PBS. This washing step was repeated once over and the optical density $\left(\mathrm{OD}_{600}\right)$ was adjusted to $\mathrm{OD}_{600}=0.2\left(\sim 10^{6} \mathrm{CFU} / \mathrm{ml}\right)$ for B. cereus and $\mathrm{OD}_{600}=0.02\left(\sim 10^{6} \mathrm{CFU} / \mathrm{ml}\right)$ for S. epidermidis.

\subsection{Experimental Setup and Optical Reflectivity Measurements}

PSiM samples were integrated in a custom-built polycarbonate fluidic cell. A fiber-coupled Ocean Optics JAZ spectrometer and a 10-mW halogen light source were used to record reflectivity spectra. Data was recorded every $10 \mathrm{~s}$, with a spectral acquisition time of $1 \mathrm{~s}$ over a wavelength rage of 500-800 nm. Analytes were injected at flow speed of 15 to $20 \mu \mathrm{L} / \mathrm{min}$ using a Fluigent LINEUPTM fluidic set up. The obtained optical data was analyzed using the RIFTS method in order to obtain the effective optical thickness, EOT $=2 n L$, with $n$ being the refractive index and $L$ the porous layer thickness. The relative change in EOT overtime was computed as a percentage, such that

$$
\frac{\triangle E O T}{E O T_{0}}=\frac{E O T_{t}-E O T_{0}}{E O T} * 100[\%] .
$$

The significance of the relative EOT shift was then established using a student $t$-test with a $5 \%$ confidence level, with a negative control test in PBS as reference.

\subsection{Real-Time Detection of B. cereus in PBS on PSi layer and PSi membranes}

The protocol for bacteria detection on a PSi membrane is illustrated in Figure 2. First $500 \mu \mathrm{L}$ of purified PlyB221 were added to $4.5 \mathrm{~mL}$ of exponential phase B. cereus resuspended in PBS, so as to reach a final protein concentration of $100 \mu \mathrm{g} / \mathrm{mL}$. The $5 \mathrm{~mL}$ final volume was sufficient for at least 4 detections. The suspension was then incubated for $30 \mathrm{~min}$ at $30^{\circ} \mathrm{C}$. Before flowing the bacterial lysate, PBS solution was injected at 15 to $20 \mu \mathrm{L} / \mathrm{min}$ for $60 \mathrm{~min}$ and reference measurements were performed. $B$. cereus lysate suspensions were injected at the same flow speed. Optical measurements were carried out every $10 \mathrm{~s}$ for $60 \mathrm{~min}$. The relative EOT was then extracted from these measurements using the method described above. A control test, with only PlyB221 at the same concentration was also performed on both types of sensors, following the same protocol described previously. For all tests, measurements were performed at least three times. 


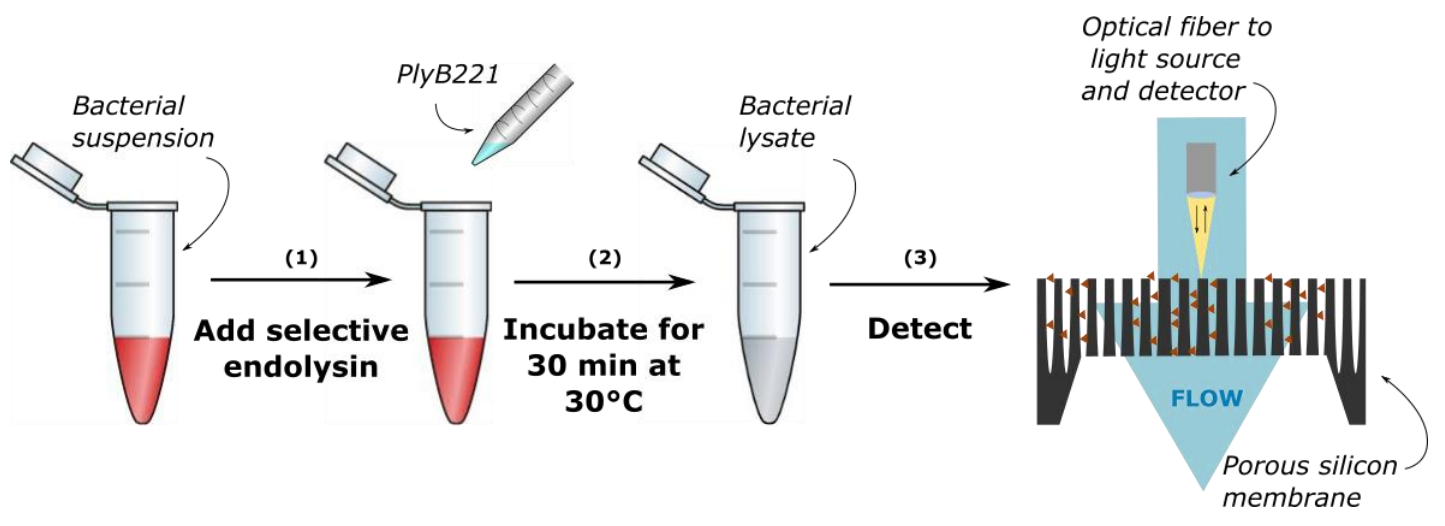

Figure 2. Protocol of bacteria detection through their lysate: (1) lysis of the bacteria using a selective endolysin, (2) incubation for $30 \mathrm{~min}$, and (3) optical detection on a Porous Silicon membrane.

\subsection{Selectivity Testing: Detection of S. epidermidis in PBS on PSi membranes}

For this experiment, $4.5 \mathrm{~mL}$ of $S$. epidermidis suspension were incubated for $30 \mathrm{~min}$ at $30{ }^{\circ} \mathrm{C}$ with the $500 \mu \mathrm{L}$ of PlyB221 endolysin $(1 \mathrm{mg} / \mathrm{ml})$. This final volume was sufficient for at least 4 detections. Reference measurements in PBS were performed for 5 to $15 \mathrm{~min}$. The bacterial suspension was injected at a flow speed of 15 to $20 \mu \mathrm{L} / \mathrm{min}$ and optical measurements were performed every $10 \mathrm{~s}$ for $60 \mathrm{~min}$. The relative EOT shift was computed as described previously.

\section{Results}

\subsection{PSi-Based Biosensor Characterization}

The effective optical thickness of Porous Silicon is strongly dependent on its refractive index. When an analyte penetrates the pores, the refractive index of the porous layer increases, therefore inducing a shift in the EOT. In the case of a membrane, to make sure that the analyte remains inside the porous matrix, two approaches are possible: size exclusion or binding to the pore wall. For this project, size exclusion was chosen by accordingly selecting different pore size for each layer of the membrane. The first layer, also called the sensing layer, has an average pore size $41.1 \mathrm{~nm}$, as described in Table 1 and illustrated in Figure 3. The bacterial lysates are composed, among others, of cell wall fragments, DNA and RNA molecules, cytoplasmic liquid and ribosomes, that are assumed to penetrate the sensing layer. In order to keep the bulkier ones in the top layer, the contrast layer was designed to have a smaller pore size, as indicated in Table 1. These choices in pore size also have two other motivations: (1) they allow the endolysins to flow through the membrane and not be retained in the sensing layer and (2) they prevent non-lysed bacteria from penetrating the membrane, therefore enabling a selective detection. Figure 4 depicts a PSi membrane, with an up-close view of the transition between the top sensing layer and the contrast layer.

Table 1. Pore diameter, thickness and porosity measured for each of the three layers of the PSiM.

\begin{tabular}{cccccc}
\hline Layer & $\begin{array}{c}\text { Current density } \\
{\left[\mathbf{m A} / \mathbf{c m}^{2}\right]}\end{array}$ & $\begin{array}{c}\text { Time } \\
{[\mathbf{s}]}\end{array}$ & $\begin{array}{c}\text { Pore diameter } \\
{[\mathbf{n m}]}\end{array}$ & $\begin{array}{c}\text { Thickness } \\
{[\mu \mathrm{m}]}\end{array}$ & $\begin{array}{c}\text { Porosity } \\
{[\%]}\end{array}$ \\
\hline $\begin{array}{c}\text { Sensing } \\
\text { layer } \\
\begin{array}{c}\text { Contrast } \\
\text { layer }\end{array}\end{array}$ & 200 & 50 & $41.1 \pm 20.4$ & $4.1 \pm 0.7$ & 75.4 \\
$\begin{array}{c}\text { Support } \\
\text { layer }\end{array}$ & 50 & 1500 & $14.6 \pm 7.8$ & $22.8 \pm 6.8$ & 48.5 \\
\hline
\end{tabular}

* The thickness and porosity could not be accurately measured, as part of the layer was etched away during the DRIE step. 


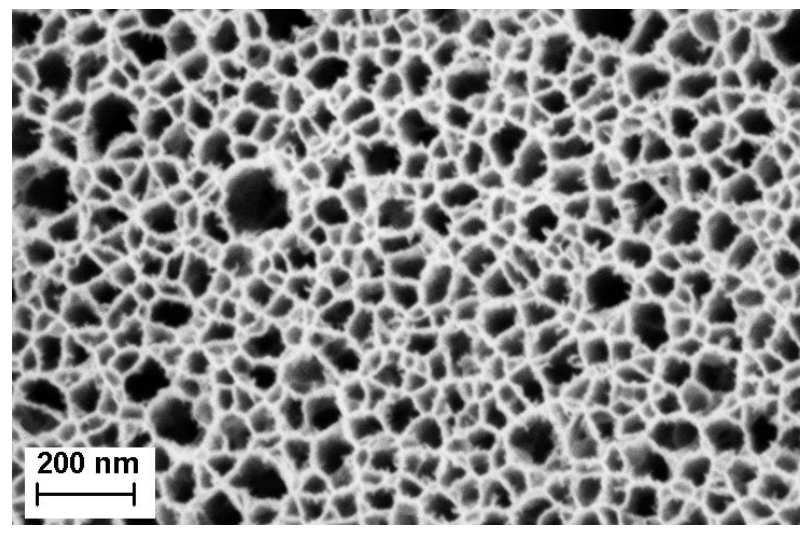

Figure 3. Scanning electron microscopy (SEM) image of the top layer Porous Silicon membrane. The average pore size is $\sim 41 \mathrm{~nm}$, with a standard deviation of $\sim 20 \mathrm{~nm}$.

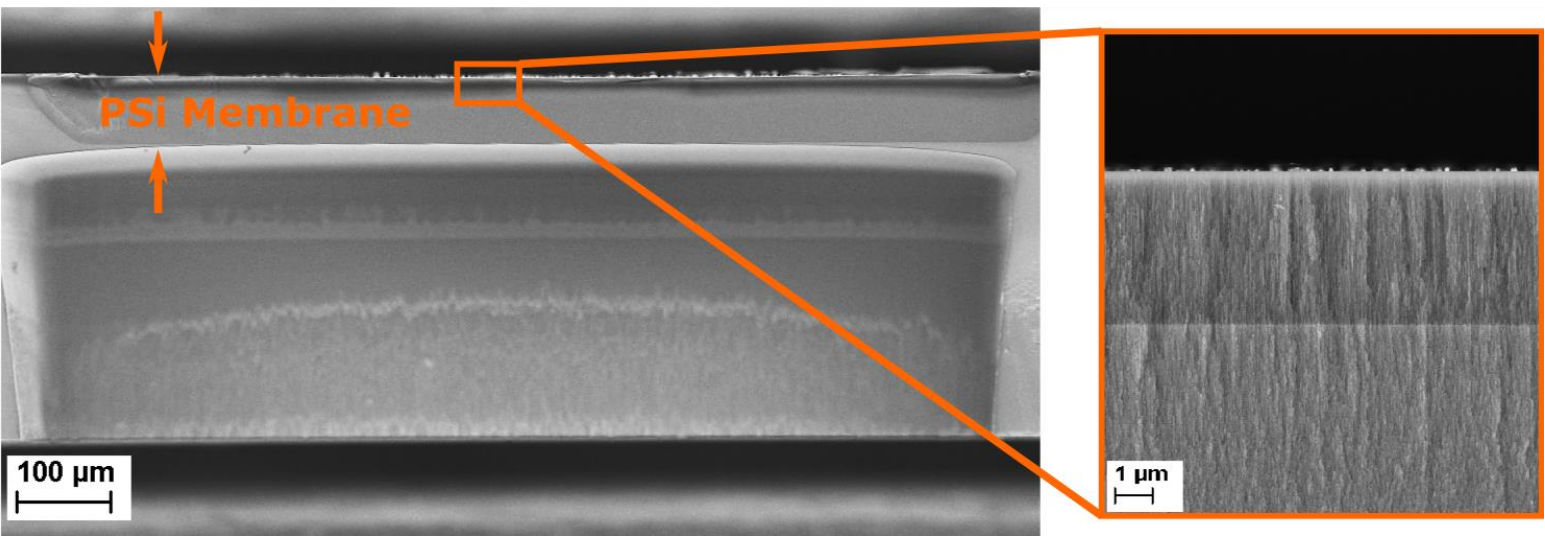

Figure 4. Scanning electron microscopy (SEM) cross-section image of a multi-layered Porous Silicon membrane. The inset shows a close-up of the top of the porous membrane, in which the sensing and the contrast layers can be identified.

\subsection{B. cereus lysate Detection PSi layers and PSi membranes}

In order to establish the added-value of a flow-through approach to the optical detection with respect to the traditional flow-over approach, the performances of PSi membranes were compared to those measured on PSi layers.

The average relative EOT shift measured on PSi layers, in a flow-over approach, is presented in Figure 5, a. No distinction could be made between the bacterial lysate detection and the control tests using either the buffer or the endolysin suspension. Both control tests induced minute decreases of the relative EOT: on average $-0.24 \%$ and $-0.01 \%$ after $1 \mathrm{~h}$ for PBS and PlyB221, respectively. A small increase of relative EOT was measured in presence of bacteria lysate, namely $0.05 \%$, but this decrease was not significant when compared to the noise level. This noise level was calculated based on the overall standard deviation of the signal in PBS and was expressed as $3 \sigma=1.08 \%$.

The performances of PSi membranes for the same three tests in flow-through operation are illustrated in Figure 5b. The buffer control test induced a decrease in relative EOT of $-0.35 \%$ after 1 $h$. The control test with only PlyB221 gave rise to a $0.28 \%$ increase of relative EOT. This increase was however not significant and remained below the noise level, which was calculated in the same manner described previously and was equal to $0.83 \%$ in the case of PSi membranes. Upon the penetration of bacterial lysate inside the membrane, a significant increase of relative EOT was measured, exceeding the noise level after $6 \mathrm{~min}$ and reaching an average $+2.35 \%$ after $1 \mathrm{~h}$. 

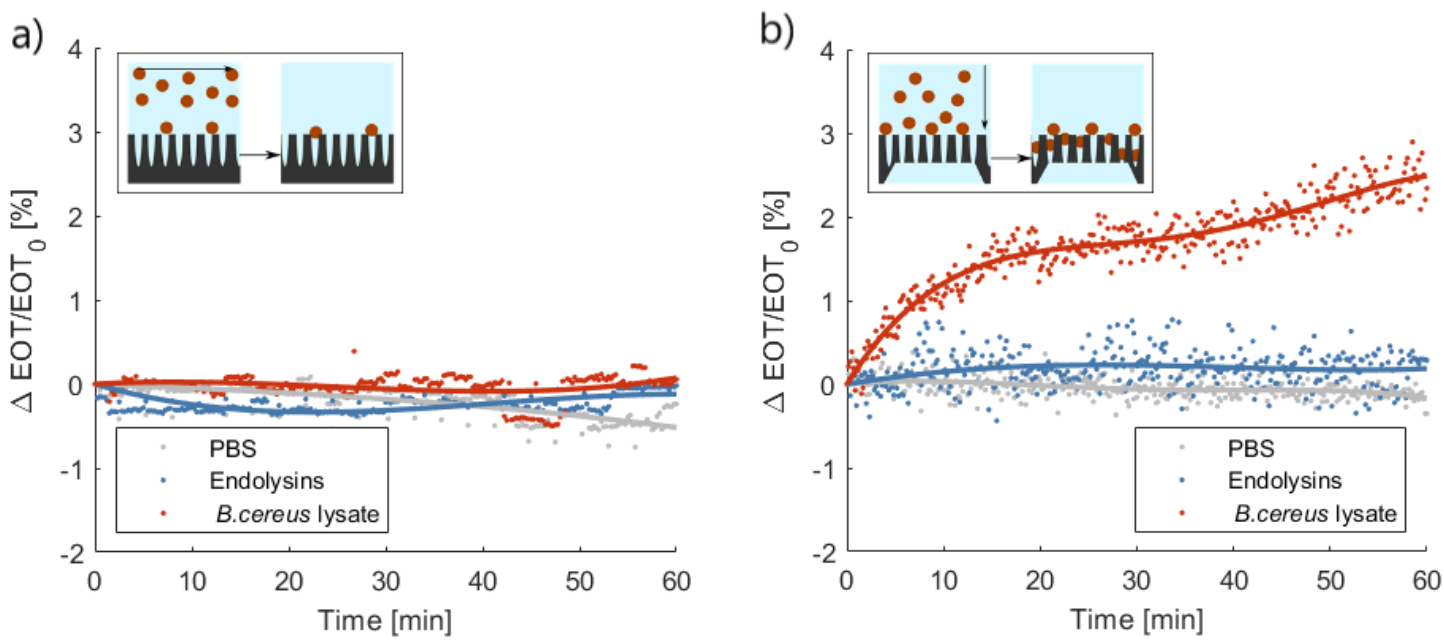

Figure 5. Characteristic relative EOT shift measured on (a) a PSi layer or (b) a PSi membrane for $1 \mathrm{~h}$ in PBS, in a PlyB221 suspension and in a B. cereus lysate $(n \geq 3)$. In a), the inset illustrates the flowover approach; there was no significant shift visible during the detection of either PlyB221 or bacterial lysate. In (b), the inset illustrates the flow-through approach; there was a significant shift in the relative EOT during the detection of bacterial lysate.

\subsection{Selectivity Testing with S. epidermidis}

To demonstrate the selectivity of the sensing platform, a negative control test was performed using a $S$. epidermidis. The relative EOT shift observed for this negative control test is depicted in Figure 6, where it is compared to control in PBS and with PlyB221 only to the detection of B. cereus lysate. The detection using $S$. epidermidis induced no significant shift in relative EOT. After $1 \mathrm{~h}$, the relative EOT was increased by $0.25 \%$, which is comparable to the control test with only PlyB221.

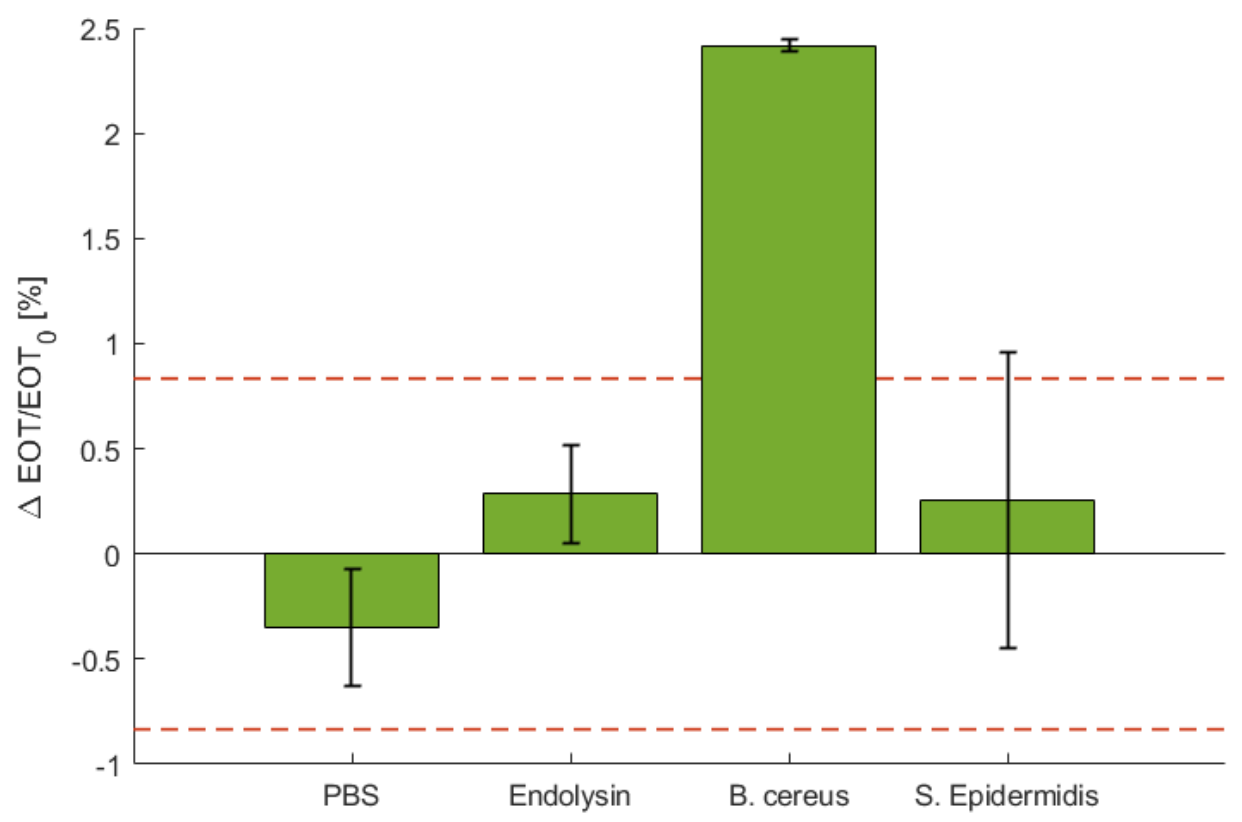

Figure 6. Characteristic relative EOT shift measured on a PSi membrane after $1 \mathrm{~h}$ in PBS, in a PlyB221 suspension, in a $B$. cereus lysate and in a $S$. epidermidis suspension $(n \geq 3)$. The dashed red line represents the noise level, fixed as $3 \sigma$ of the signal measured in PBS. Only the detection of B. cereus lysate induced a significant shift.

\section{Discussion}


Porous Silicon membranes are promising biosensors: with their flow-through operation, they overcome the lack of sensitivity of flow-over PSi-based biosensors and are characterized by short response times [18-22]. Moreover, they do not require any stratagems to transport and concentrate the analyte on the transducer. In this work, we demonstrate once again the potential of these detection platforms and focus on their use for the detection of bacteria. PSiMs were fabricated using standard microfabrication techniques and electrochemical etching. The full fabrication process took less than a week, and dozens of samples could be produced in one go. No functionalization was applied to the sensors, as the selectivity was based on the use of endolysins. Endolysins are phage-encoded enzymes that induce bacterial lysis for certain targeted strains. In this work, PlyB221 was used, targeting $B$. cereus, whose efficiency is demonstrated in [26].

Combining PSiMs and the use of endolysins produced an innovative biosensing platform able to detect $B$. cereus lysate, with an initial concentration of $10^{6} \mathrm{CFU} / \mathrm{ml}$, in less than $10 \mathrm{~min}$. In flow-over PSi-based biosensors, similar concentrations could not be detected. Three negative control tests were carried out: one in PBS, one with only PlyB221 and one in which B. cereus was replaced by $S$. epidermidis. The PBS control induces a slight decrease of relative EOT. This can be explained by the slow oxidation and dissolution that PSi undergoes in aqueous media $[27,28]$. This effect can be minimized by chemically modifying the pore surface using either hydrosilylation [29], thermal hydrocarbonisation [30] or atomic layer deposition (ALD) of oxides [31]. Adequate passivation may also help reducing the noise level of the optical sensing, as demonstrated by Rasson et al. with the use of ALD [31]. The second control test, which consisted in flowing a PlyB221 suspension through the sensor for $1 \mathrm{~h}$, resulted in a slight increase of the relative EOT. While it was expected that the endolysins pass through the membrane, this increase indicates that they were partly retained. Two hypotheses might explain this effect: (1) a minor size exclusion effect, which is understandable since there is a large pore size distribution visible in Figure 3 and (2) the binding of proteins to the pore walls. For the third negative control test, S. epidermidis was added to the PlyB221. The observed shift in relative EOT is similar to the one observed with only PlyB221. This confirms that bacteria, when not lysed, are not able to penetrate the membrane, thus demonstrating the selectivity of the sensing platform.

While most PSiM-based sensors rely on functionalization to capture the analyte $[18,21,22]$, the biosensor presented in this work bases the capture on a size exclusion effect. This novelty has several benefits: the lack of functionalization considerably shortens the production time of the sensors, puts no requirements on the storage and detection conditions and, finally, enables the use of sensors from the same batch for the detection of different strains of bacteria, as long as a selective endolysin is available. The response time for this study is comparable to functionalized PSiMs [18,21,22] and since no rinsing is required to remove unbound species, the total detection time (which includes both lysis and optical monitoring) can be reduced to less than $1 \mathrm{~h}$. Another major advantage is the reduced volume of analyte that is needed: less than $1 \mathrm{~mL}$ is required for the detection. While the detected bacteria concentration remains high compared to other PSi bacteria sensors [12,13,32,33], there is much room for improvement. Further studies should therefore aim to lower the detection limit to competitive levels $\left(<10^{3} \mathrm{CFU} / \mathrm{mL}\right)$ by improving the stability of the sensor and reducing the noise level of the optical signal. The multiplexing capabilities of the detection platform could also easily be proven, by using other bacteria and selective endolysins pairs.

\section{Conclusions}

In conclusion, we fabricated an innovative biosensor for the detection of bacteria through their lysate, by combining the use of both optically monitored Porous Silicon membranes and selective endolysins. We showed promising results in terms of sensitivity, selectivity, and speed of response by demonstrating the targeted detection of $10^{6} \mathrm{CFU} / \mathrm{ml}$ of B. cereus lysate in less than $10 \mathrm{~min}$. These results, added to the easy fabrication and low design cost, pave the way for the development of a widespread multi-strain bacteria sensor. 
Author Contributions: Conceptualization, R.V. and L.A.F.; methodology, R.V. and A.L.; software, R.V.; validation, R.V.; formal analysis, R.V.; investigation, R. V. and A.L.; resources, J.M. and L.A.F.; data curation, R.V.; writing - original draft preparation, R.V.; writing - review and editing, A.L., J.M. and L.A.F.; visualization, R.V.; supervision, J.M. and L.A.F.; project administration, J.M. and L.A.F.; funding acquisition, J.M. and L.A.F. All authors have read and agreed to the published version of the manuscript.

Funding: This research was funded by National Fund for Scientific Research (FRIA grant to R.V. and FNRS grant to J.M.) and the Research Department of the Communauté française de Belgique (Concerted Research Action, ARC no.17/22-084, grant to A.L.).

Acknowledgments: We would like to thank Jonathan Rasson for his help during the conceptualization stages of this project.

Conflicts of Interest: The authors declare no conflict of interest. The funders had no role in the design of the study; in the collection, analyses, or interpretation of data; in the writing of the manuscript, or in the decision to publish the results.

\section{References}

1. Lazcka, O.; Campo, F.J.D.; Muñoz, F.X. Pathogen detection: A perspective of traditional methods and biosensors. Biosens. Bioelectron. 2007, 22, 1205-1217, doi:10.1016/j.bios.2006.06.036.

2. Zourob, M.; Ripp, S. Bacteriophage-Based Biosensors. In Recognition Receptors in Biosensors; Zourob, M., Ed.; Springer: New York, NY, USA, 2010; pp. 415-448, ISBN 978-1-4419-0919-0.

3. Couniot, N.; Vanzieleghem, T.; Rasson, J.; Van Overstraeten-Schlögel, N.; Poncelet, O.; Mahillon, J.; Francis, L.A.; Flandre, D. Lytic enzymes as selectivity means for label-free, microfluidic and impedimetric detection of whole-cell bacteria using ALD-A12O3 passivated microelectrodes. Biosens. Bioelectron. 2015, 67, 154-161, doi:10.1016/j.bios.2014.07.084.

4. Paczesny, J.; Richter, Ł.; Hołyst, R. Recent Progress in the Detection of Bacteria Using Bacteriophages: A Review. Viruses 2020, 12, 845, doi:10.3390/v12080845.

5. Arshavsky-Graham, S.; Massad-Ivanir, N.; Segal, E.; Weiss, S. Porous Silicon-Based Photonic Biosensors: Current Status and Emerging Applications. Anal. Chem. 2019, 91, 441-467, doi:10.1021/acs.analchem.8b05028.

6. Tieu, T.; Alba, M.; Elnathan, R.; Cifuentes-Rius, A.; Voelcker, N.H. Advances in Porous Silicon-Based Nanomaterials for Diagnostic and Therapeutic Applications. Adv. Ther. 2019, 2, 1800095, doi:10.1002/adtp.201800095.

7. Sailor, M.J. Porous Silicon in Practice: Preparation, Characterization and Applications; Wiley: Hoboken, NJ, USA, 2012; ISBN 978-3-527-64191-8.

8. Zhuo, S.; Xun, M.; Li, M.; Kong, X.; Shao, R.; Zheng, T.; Pan, D.; Li, J.; Li, Q. Rapid and Label-free Optical Assay of S-layer Protein with High Sensitivity Using TiO2-coated Porous Silicon-based Microfluidic Biosensor. Sens. Actuators B Chem. 2020, 128524, doi:10.1016/j.snb.2020.128524.

9. Maniya, N.H.; Srivastava, D.N. Fabrication of Porous Silicon based label-free optical biosensor for heat shock protein 70 detection. Mater. Sci. Semicond. Process. 2020, 115, 105126, doi:10.1016/j.mssp.2020.105126.

10. Kumar, D.N.; Pinker, N.; Shtenberg, G. Inflammatory biomarker detection in milk using label-free porous SiO2 interferometer. Talanta 2020, 220, 121439, doi:10.1016/j.talanta.2020.121439.

11. Kumar, D.N.; Pinker, N.; Shtenberg, G. Porous Silicon Fabry-Pérot Interferometer for N -Acetyl- $\beta$ - D Glucosaminidase Biomarker Monitoring. ACS Sens. 2020, 5, 1969-1976, doi:10.1021/acssensors.0c00348.

12. Massad-Ivanir, N.; Shtenberg, G.; Raz, N.; Gazenbeek, C.; Budding, D.; Bos, M.P.; Segal, E. Porous SiliconBased Biosensors: Towards Real-Time Optical Detection of Target Bacteria in the Food Industry. Sci. Rep. 2016, 6, doi:10.1038/srep38099.

13. Tang, Y.; Li, Z.; Luo, Q.; Liu, J.; Wu, J. Bacteria detection based on its blockage effect on silicon nanopore array. Biosens. Bioelectron. 2016, 79, 715-720, doi:10.1016/j.bios.2015.12.109.

14. Gongalsky, M.B.; Koval, A.A.; Schevchenko, S.N.; Tamarov, K.P.; Osminkina, L.A. Double Etched Porous Silicon Films for Improved Optical Sensing of Bacteria. J. Electrochem. Soc. 2017, 164, B581-B584, doi:10.1149/2.1821712jes.

15. Rajapaksha, P.; Elbourne, A.; Gangadoo, S.; Brown, R.; Cozzolino, D.; Chapman, J. A review of methods for the detection of pathogenic microorganisms. Analyst 2019, 144, 396-411, doi:10.1039/C8AN01488D. 
16. Arshavsky-Graham, S.; Massad-Ivanir, N.; Paratore, F.; Scheper, T.; Bercovici, M.; Segal, E. On Chip Protein Pre-Concentration for Enhancing the Sensitivity of Porous Silicon Biosensors. ACS Sens. 2017, 2, 1767-1773, doi:10.1021/acssensors.7b00692.

17. Canham, L. Handbook of Porous Silicon; Springer: New York, NY, USA, 2014; ISBN 978-3-319-05743-9.

18. Zhao, Y.; Gaur, G.; Retterer, S.T.; Laibinis, P.E.; Weiss, S.M. Flow-Through Porous Silicon Membranes for Real-Time Label-Free Biosensing. Anal. Chem. 2016, 88, 10940-10948, doi:10.1021/acs.analchem.6b02521.

19. Kumar, N.; Froner, E.; Guider, R.; Scarpa, M.; Bettotti, P. Investigation of non-specific signals in nanoporous flow-through and flow-over based sensors. Analyst 2014, 139, 1345, doi:10.1039/c3an01996a.

20. Martín-Sánchez, D.; Ponce-Alcántara, S.; García-Rupérez, J. Sensitivity Comparison of a Self-Standing Porous Silicon Membrane under Flow-Through and Flow-Over Conditions. IEEE Sens. J. 2019, 19, 32763281, doi:10.1109/JSEN.2019.2893885.

21. Zhao, Y.; Gaur, G.; Mernaugh, R.L.; Laibinis, P.E.; Weiss, S.M. Comparative Kinetic Analysis of ClosedEnded and Open-Ended Porous Sensors. Nanoscale Res. Lett. 2016, 11, doi:10.1186/s11671-016-1614-3.

22. $\mathrm{Yu}, \mathrm{N}$.; $\mathrm{Wu}, \mathrm{J}$. Rapid and reagentless detection of thrombin in clinic samples via microfluidic aptasensors with multiple target-binding sites. Biosens. Bioelectron. 2019, 146, 111726, doi:10.1016/j.bios.2019.111726.

23. Leïchlé, T.; Bourrier, D. Integration of lateral Porous Silicon membranes into planar microfluidics. Lab Chip 2015, 15, 833-838, doi:10.1039/C4LC01094A.

24. He, Y.; Vasconcellos, D.S.D.; Bardinal, V.; Bourrier, D.; Imbernon, E.; Salvagnac, L.; Laborde, A.; Dollat, X.; Leichlé, T. Lateral Porous Silicon Interferometric Transducer for Sensing Applications. In Proceedings of the 2018 IEEE SENSORS, New Delhi, India, 28-31 October 2018, pp. 1-3.

25. He, Y.; Leïchlé, T. Fabrication of lateral Porous Silicon membranes for planar microfluidics by means of ion implantation. Sens. Actuators B Chem. 2017, 239, 628-634, doi:10.1016/j.snb.2016.08.035.

26. Leprince, A.; Nuytten, M.; Gillis, A.; Mahillon, J. Characterization of PlyB221 and PlyP32, Two Novel Endolysins Encoded by Phages Preying on the Bacillus cereus Group. Viruses 2020, 12, 1052, doi:10.3390/v12091052.

27. Janshoff, A.; Dancil, K.-P.S.; Steinem, C.; Greiner, D.P.; Lin, V.S.-Y.; Gurtner, C.; Motesharei, K.; Sailor, M.J.; Ghadiri, M.R. Macroporous p-Type Silicon Fabry-Perot Layers. Fabrication, Characterization, and Applications in Biosensing. J. Am. Chem. Soc. 1998, 120, 12108-12116, doi:10.1021/ja9826237.

28. Dancil, K.-P.S.; Greiner, D.P.; Sailor, M.J. A Porous Silicon Optical Biosensor: Detection of Reversible Binding of IgG to a Protein A-Modified Surface. J. Am. Chem. Soc. 1999, 121, 7925-7930, doi:10.1021/ja991421n.

29. Stewart, M.P.; Robins, E.G.; Geders, T.W.; Allen, M.J.; Choi, H.C.; Buriak, J.M. Three methods for stabilization and functionalization of Porous Silicon surfaces via hydrosilylation and electrografting reactions. Phys. Status Solidi (A) Appl. Res. 2000, 182, 109-115, doi:10.1002/1521396X(200011)182:1<109::AID-PSSA109>3.0.CO;2-\#.

30. Salonen, J.; Björkqvist, M.; Laine, E.; Niinistö, L. Stabilization of Porous Silicon surface by thermal decomposition of acetylene. Appl. Surf. Sci. 2004, 225, 389-394, doi:10.1016/j.apsusc.2003.10.028.

31. Rasson, J.; Francis, L.A. Improved Stability of Porous Silicon in Aqueous Media via Atomic Layer Deposition of Oxides. J. Phys. Chem. C 2018, 122, 331-338, doi:10.1021/acs.jpcc.7b08569.

32. Tenenbaum, E.; Segal, E. Optical biosensors for bacteria detection by a peptidomimetic antimicrobial compound. Analyst 2015, 140, 7726-7733, doi:10.1039/C5AN01717C.

33. Yaghoubi, M.; Rahimi, F.; Negahdari, B.; Rezayan, A.H.; Shafiekhani, A. A lectin-coupled Porous Siliconbased biosensor: label-free optical detection of bacteria in a real-time mode. Sci. Rep. 2020, 10, 16017, doi:10.1038/s41598-020-72457-x.

(C) 2020 by the authors. Submitted for possible open access publication under the terms and conditions of the Creative Commons Attribution (CC BY) license (http://creativecommons.org/licenses/by/4.0/). 